\title{
Prognostic Factors in 77 Curative Chest Wall Resections for Isolated Breast Cancer Recurrence
}

\author{
Carmen C. van der Pol, MD ${ }^{1,3}$, Albertus N. van Geel, MD, PhD ${ }^{1}$, Marian B. E. Menke-Pluymers, MD, $\mathrm{PhD}^{\mathbf{1}}$, \\ Paul I. M. Schmitz, $\mathbf{P h D}^{2}$, and Titia E. Lans, MD, $\mathbf{P h D}^{1}$ \\ ${ }^{1}$ Department of Surgical Oncology, Erasmus Medical Centre/Daniel den Hoed Cancer Centre, Rotterdam, \\ The Netherlands; ${ }^{2}$ Department of Biostatistics, Erasmus Medical Centre/Daniel den Hoed Cancer Centre, Rotterdam, \\ The Netherlands; ${ }^{3}$ Department of Surgery, Reinier de Graaf Gasthuis, Delft, The Netherlands
}

\begin{abstract}
Background. Full-thickness chest wall resection (CWR) is the preferred treatment for breast cancer (BC) patients with extensive isolated locoregional recurrence. It remains a challenge to select patients that will benefit most from this treatment. The aim of this study was to define prognostic factors in patients who undergo CWR with curative intent.
\end{abstract}

Methods. BC patients who underwent a CWR with curative intent for recurrence of disease between 1986 and 2006 were included in this retrospective study. Twenty-two factors were studied in a univariate analyses, and multivariate stepwise Cox regression analyses was performed.

Results. Seventy-seven patients were included in this study. The 5-year overall survival was $25 \%$. There was one postoperative death. Univariate analyses showed that three prognostic factors were significantly correlated with OS and disease-free survival: (1) interval between primary treatment and CWR ( $P=.02$ and .004 , respectively), (2) chemotherapy for recurrence $(P=.05$ and .05 , respectively), and (3) resection specimen smaller than $150 \mathrm{~cm}^{2}(P=.03$ and .009 , respectively). An interval lasting $>10$ years between primary treatment and CWR remained statistically significantly correlated with better overall survival and disease-free survival after multivariate analyses.

Conclusions. CWR is a safe treatment in patients who have isolated extensive $\mathrm{BC}$ recurrence. The best survival outcome was seen in patients after a disease-free interval of

(C) The Author(s) 2009. This article is published with open access at Springerlink.com

First Received: 11 May 2009;

Published Online: 12 August 2009

A. N. van Geel, MD, PhD

e-mail: a.n.vangeel@erasmusmc.nl $\geq 10$ years. Existing data show that adjuvant radiotherapy and adjuvant hormone therapy for estrogen-positive tumors improves overall survival. Neoadjuvant chemotherapy may be considered in individual patients.

Locoregional recurrence (LRR) after modified radical mastectomy (MRM) for breast cancer (BC) is a worrying event for both doctor and patient. Despite optimal local treatment with curative intent, $60 \%$ of the patients will develop distant metastases, although at the time of the first sign of LRR, two out of three patients have no any other signs of BC recurrence. ${ }^{1,2}$

Recently, the results of a prospective series of 1957 patients who underwent MRM have been published after a median follow-up of 6 years. The LRR rate was 9\%, and $3 \%$ of these patients had concomitant distant metastases. ${ }^{3}$ Early detection of LRR and small tumor size predicted better prognosis. $^{4-7}$

Options for local treatment of LRR include wide local excision and/or radiotherapy whether or not in combination with hyperthermia. ${ }^{8}$ However, for small lesions, the type of local treatment did not affect the final outcome. ${ }^{9}$ Another study on the treatment of LRR after mastectomy concluded that surgery combined with radiotherapy was the best treatment option, with a 5-year disease-free survival (DFS) of $27 \% .{ }^{10}$ In patients who initially underwent breast-conserving therapy (BCT) for BC, radiotherapy cannot be included in the multimodal treatment for LRR. Therefore, salvage mastectomy has to be performed, or even more extensive surgery when the chest wall is involved. In patients with LRR who were initially treated with BCT or MRM, the results are similar. ${ }^{2,9}$ After MRM and BCT, the 5-year survival rates were $58 \%$ and $59 \%$, with subsequent local control rates of $61 \%$ and $63 \%$. In this study, aggressive multimodal therapy with curative intent is recommended. 
In the literature, adequate definitions for LRR, the extent of LRR and the type of treatment these patients received are lacking. Often it is unclear whether patients with extensive LRR underwent chest wall resection (CWR) or not.

As a result of the heterogeneity of LRR invading the chest wall and the scarcity of published data, there are no evidence-based guidelines for the best treatment results.

Radiotherapy as monotherapy for extensive LRR does not result in complete remission. Consequently, surgery may be the best treatment option, even if it means extensive surgical resection with reconstruction of the chest wall. CWR is expected to regain local control, improve the prognosis, and/or achieve good palliation, in combination with limited morbidity and mortality.

In 1907, Sauerbruch introduced an extensive thoracic wall resection procedure for recurrent breast carcinoma. ${ }^{11}$ Since then, several reports have been published on these procedures. There are a few large series (approximately 15), and some of them were performed at the same institute-for example, M. D. Anderson Cancer Center in the United States, the Instituto Nazionale in Italy, and Kinki Hospital in Japan. ${ }^{12-20}$

The present retrospective single-center study of CWR for recurrent $\mathrm{BC}$ aims to describe the outcome of treatment and to identify prognostic factors in patients who were treated with curative intent.

\section{MATERIALS AND METHODS}

According to our retrospective database on CWRs for malignant tumors or radiation ulcers on the chest wall in the period 1986 to 2006, a total of 92 of 229 consecutive patients had undergone CWR for recurrent BC.

CWR was defined as either extended soft tissue resection with broad margins that required reconstruction of the soft tissue component, or full-thickness CWR that included at least one rib or part of the sternum (Fig. 1). Several types of inlay have been used for skeletal reconstruction over the 20 -year study period. In the first few years, homologous dura mater has been used (Lyodura, B. Braun, Melsungen, FRG), later to be replaced by polyurethane (Neuropatch, B. Braun, Melsungen, FRG) as an artificial inlay. In some cases, polyglactin (Vicryl, Ethicon) was used. Patients operated on after 2004 received a double-layer polypropylene-polytetrafluoroethylene mesh (Composix). Standard soft tissue reconstruction was performed with pedicled omentoplasty unless primary closure could be achieved. Surgical aspects of the CWR technique at our hospital have been described previously. ${ }^{21}$

Fifteen of the 92 patients were excluded from this study because the CWR was for palliative reasons, such as

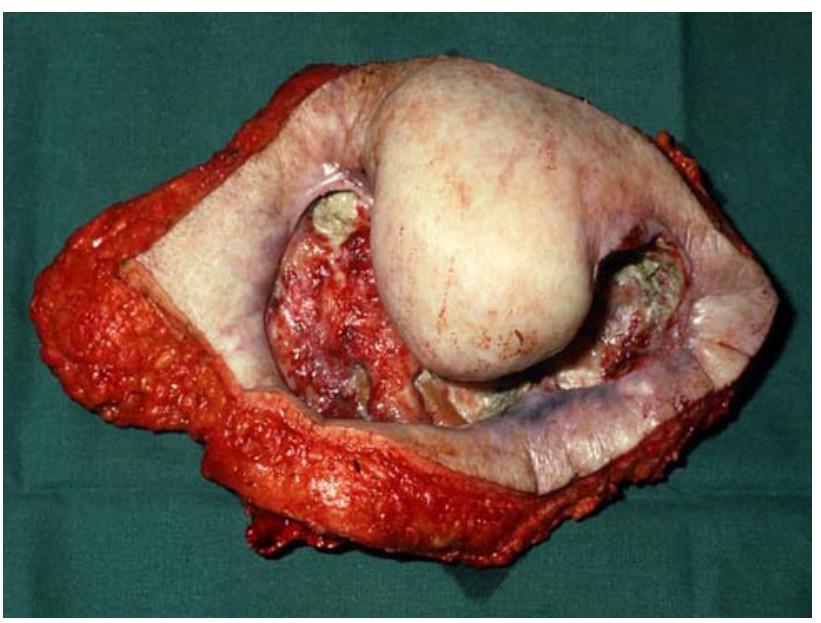

FIG. 1 Full-thickness chest wall resection for recurrent breast cancer, including the remaining breast and radiation ulcer with osteoradionecrosis of the costae

fungating ulcers or symptomatic progression of LRR, and the prognosis was reasonable despite the presence of distant metastases and limited life expectancy. The CWR was considered to be potentially curative when preoperative evaluation showed that the resection could be radical and the patient had no evidence of distant metastases. Therefore, at least a computed tomographic scan of the lung and of the liver, a bone scintigraphy, and mammography were performed. Patients who had received previous radiotherapy and/or systemic therapy for this LRR were not excluded from our analysis. Severe complications were defined as those that required prolonged hospitalization or resurgery.

Two clinical end points were set: (1) overall survival (OS) defined as the time from CWR to the date of death or the date of the last visit, whichever occurred first; (2) DFS, defined as the time from CWR to the date of local recurrence, or regional recurrence, or the date of death, or the date of the last visit, whichever occurred first.

Detailed clinical information was obtained from the medical records and pathology reports. Patient, tumor, and treatment characteristics at initial presentation with $\mathrm{BC}$ (Table 1) and treatment and outcome factors at the time of CWR (Table 2) were collected.

Univariate analysis was performed by the Kaplan-Meier method and the log rank test. Multivariate analysis was performed to determine the independent prognostic values of the statistically significant univariate factors by Cox's proportional hazard model (stepwise backward selection). Significance was set at a $P$ value of $\leq .05$. All the statistical analyses were performed with Stata, version 9.2 (StataCorp, College Station, TX). 
TABLE 1 Demographics at the time of initial treatment before chest wall resection for recurrent breast cancer

Factor $n(\%)$

$$
\begin{array}{r}
\text { Age (y) } \\
<40 \\
\geq 40
\end{array}
$$

Treatment

BCT

MRM

Radiotherapy alone

$47(61)$

$27(35)$

3 (4)

T status

$\mathrm{T} 1$

$\mathrm{T} 2$

T3

T4

Tx

$\mathrm{N}$ status

NO

N1

N2

N3

$\mathrm{NX}$

Adjuvant chemotherapy

Yes

No

Adjuvant hormone therapy

Yes

No

19 (25)

$45(58)$

$6(8)$

$6(8)$

1 (1)

45 (58)

28 (37)

3 (4)

0 (0)

1 (1)

11 (14)

66 (86)

19 (25)

58 (75)

Adjuvant radiotherapy

Yes

44 (57)

No

Receptor status ${ }^{\mathrm{a}}$

ER positive

41 (53)

ER negative

ER unknown

PR positive

PR negative

PR unknown

9 (12)

28 (36)

$33(43)$

16 (21)

$\overline{B C T}$ breast-conserving therapy, MRM modified radical mastectomy, $E R$ estrogen receptor, $P R$ progesterone receptor

${ }^{\text {a }}$ Not tested in univariate analysis because too much data are missing

\section{RESULTS}

In 77 patients $\mathrm{CWR}$ was performed for recurrent $\mathrm{BC}$ that fulfilled our above-described curative-intent criteria. Indications were local recurrence in the chest wall $(n=41)$ and regional recurrence in the axillary lymph nodes $(n=9)$, or in the internal mammary lymph nodes $(\mathrm{n}=27)$. The last group of patients is described in detail elsewhere. ${ }^{22}$
TABLE 2 Characteristics of 77 patients at the time of chest wall resection for recurrent breast cancer

Factor $n(\%)$

Age (y)

$<60$

$43(56)$

$\geq 60$

$34(44)$

Interval since primary treatment for CWR

$\leq 10 \mathrm{y}$

49 (64)

$>10 \mathrm{y}$

Unknown

Pre-CWR hyperthermia

No

67 (87)

Yes

$10(13)$

Pre-CWR hormone therapy

No

$62(81)$

Yes

15 (19)

Pre-CWR chemotherapy

No

66 (86)

Yes

Pre-thorax radiotherapy

No

$63(82)$

Yes

$14(18)$

Recurrence rate

First

$55(65)$

Second

$10(13)$

Third

8 (10)

Fourth

Seventh

$1(1)$

Resected specimen

Skin + soft tissue

$14(18)$

Bone (with or without lung)

$63(82)$

Size of resection surface

$<150 \mathrm{~cm}^{2}$

$62(81)$

$\geq 150 \mathrm{~cm}^{2}$

15 (19)

Radicality

No

Yes

49 (64)

Bone invasion

No

Yes

45 (58)

Ulceration

No

67 (87)

Yes

$10(13)$

Reconstruction of bone

No

$17(22)$

Yes

$60(78)$

Reconstruction of skin

$51(66)$

No

$26(34)$ 
TABLE 2 continued

\begin{tabular}{ll}
\hline Factor & $n(\%)$ \\
\hline Adjuvant treatment & \\
No & $37(48)$ \\
Yes & $40(52)$ \\
\hline
\end{tabular}

$C W R$ chest wall resection

\section{Factors at the Time of Primary Treatment}

Table 1 shows the demographic data at the time of initial treatment for BC. Age at the time of diagnosis was 28 to 86 (median 46) years, and $18 \%$ of the patients were younger than 40 years. MRM had been performed in $61 \%$, BCT in $35 \%$, and radiotherapy in combination with chemotherapy for $\mathrm{T} 4$ tumors in $4 \%$. Postoperative radiotherapy was given in 19 of the 47 MRM patients and in 25 of the 27 BCT patients. Initial T1-T2 tumors were present in $83 \%$ of the patients, and axillary lymph nodes were negative in 59\%. Estrogen receptor-positive tumors were found in 53\%. Various schedules of adjuvant systemic treatment after MRM or BCT had been applied to 19 patients (25\%), according to the guidelines at that time.

\section{Factors at the Time of CWR}

Table 2 shows the demographic data at the time of CWR. The interval between initial treatment and CWR ranged from 0 to 33 years, with a median of 7 years. This interval was $>10$ years in $34 \%$.

Age at the time of CWR was younger than 60 years in $56 \%$. In $65 \%$ of the patients who underwent CWR, it was their first recurrence of BC. In the other 22 patients, CWR was performed because two or more episodes of recurrence had been treated unsuccessfully in the past with systemic therapy and/or radiotherapy. None of the patients had surgery of the LRR before. Full-thickness CWR with bone resection was performed in 63 patients $(82 \%)$ and bone reconstruction in 60 patients. Primary skin closure could be achieved in $66 \%$ of the patients, most of whom (84\%) underwent bone reconstruction. Soft tissue reconstruction was indicated in 33\%: in all but one patient, pedicled omentoplasty and split skin grafting were performed, while 17 patients needed soft tissue reconstruction combined with bone reconstruction.

The pathology reports described tumor-free margins (R0 resection) in $64 \%$ of the CWR specimens. Adjuvant treatment had been applied to $58 \%$ of the patients after intensive discussion in a multidisciplinary team (Table 3 ). Of the patients with no tumor-free margins, $18 \%$ received adjuvant systemic treatment, and 54\% radiotherapy and/or hyperthermia.
TABLE 3 Adjuvant treatment after chest wall resection for recurrent breast cancer $(n=37)$

\begin{tabular}{lc}
\hline Adjuvant treatment & $n(\%)$ \\
\hline Chemotherapy & $5(13)$ \\
Hormone treatment & $8(22)$ \\
Radiotherapy & $18(49)$ \\
Hyperthermia & $3(8)$ \\
Hormone treatment and radiotherapy & $2(5)$ \\
Radiotherapy and hyperthermia & $1(3)$ \\
\hline
\end{tabular}

\section{Complications}

Recovery without any complications was seen in 48 (62\%) of 77 patients. The remaining 29 patients (38\%) had moderate or severe complications. Complications that could be treated conservatively occurred in 12 patients, while 16 patients (22\%) had severe complications that required resurgery or prolonged hospitalization. One patient died within 30 days due to respiratory failure caused by pulmonary embolism.

\section{OS, DFS, Local Recurrence, and Metastases}

Median OS of the patients who underwent CWR for recurrent $\mathrm{BC}$ with curative intent was 40 months. The 1year and 5-year OS rates were $94 \%$ and $25 \%$, respectively (Fig. 1).

The 1-year and 5-year local recurrence-free rates were $81 \%$ and $51 \%$, respectively.

Median DFS was 14.5 months. The 1-year and 5-year DFS rates were $56 \%$ and $12 \%$, respectively. Median interval until (regional and distant) metastases was 18.0 months. The 1-year and 5-year metastases-free rates were $63 \%$ and $19 \%$, respectively.

\section{Univariate and Multivariate Analyses}

Univariate analysis showed that three prognostic factors were significantly related with OS and DFS: (1) interval between primary treatment and CWR $(P=.02$ and .004 , respectively), (2) chemotherapy for treatment of LRR at any time before or after CWR $(P=.05$ and .05 , respectively) and (3) resection specimen $<150 \mathrm{~cm}^{2}(P=.03$ and .009 , respectively) (Table 4).

Stepwise Cox regression analysis was performed on interval, chemotherapy, and size simultaneously. Only an interval of $>10$ years between primary treatment and CWR remained highly correlated with better OS and DFS. 
TABLE 4 Univariate analyses of 77 patients with chest wall resection for recurrent breast cancer

\begin{tabular}{|c|c|c|c|c|c|}
\hline \multirow[t]{2}{*}{ Factor } & \multicolumn{2}{|c|}{ Overall survival } & \multicolumn{3}{|c|}{ Disease-free survival } \\
\hline & $95 \% \mathrm{CI}$ & $P$ value & HR & $95 \%$ CI & $P$ value \\
\hline
\end{tabular}

Age at initial treatment

\begin{tabular}{|c|c|c|c|c|}
\hline$<40 \mathrm{y}$ & 1 & & 1 & \\
\hline$\geq 40 y$ & 1.01 & 0.99-1.03 & 0.99 & $0.98-1.01 \quad .50$ \\
\hline
\end{tabular}

Initial surgery

\begin{tabular}{lllllll} 
BCT & 1 & & \multicolumn{1}{c}{1} \\
MRM & 0.69 & $0.33-1.44$ & .32 & 0.84 & $0.43-1.62$ & .60
\end{tabular}

T status

\begin{tabular}{lllllll} 
T1 & 1 & & \multicolumn{1}{c}{1} \\
T2 & 1.22 & $0.51-2.94$ & .65 & 1.00 & $0.49-2.05$ & .99 \\
T3-T4 & 1.09 & $0.40-2.95$ & .87 & 1.47 & $0.63-3.46$ & .37
\end{tabular}

$\mathrm{N}$ status

\begin{tabular}{llllllll} 
N0 & 1 & & \multicolumn{1}{c}{1} & & \\
N1 & 0.67 & $0.32-1.40$ & .29 & 0.79 & $0.43-1.46$ & .46 \\
N2-N3 & 0.90 & $0.21-3.84$ & .88 & 0.64 & $0.15-2.69$ & .54
\end{tabular}

Initial adjuvant chemotherapy

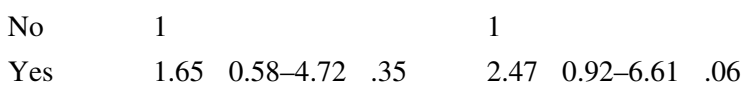

Initial adjuvant hormone therapy

$$
\begin{array}{llllllll}
\text { No } & 1 & & \multicolumn{1}{c}{1} & & \\
\text { Yes } & & 0.52 & 0.20-1.34 & .17 & 0.72 & 0.35-1.51 & .39
\end{array}
$$

Initial adjuvant radiotherapy

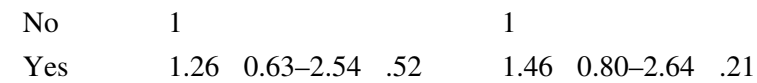

Age at CWR

$$
\begin{aligned}
& \begin{array}{llll}
<60 \text { y } & 1 & 1
\end{array} \\
& \begin{array}{lllllll}
\geq 60 \mathrm{y} & 0.99 & 0.97-1.01 & .18 & 0.99 & 0.97-1.00 & .056
\end{array}
\end{aligned}
$$

Interval prim-CWR

$$
\begin{array}{llllllll}
\leq 10 \text { y } & 1 & & & & 1 & & \\
>10 \text { y } & 0.32 & 0.12-0.84 & .02 & & 0.37 & 0.19-0.74 & \mathbf{. 0 0 4}
\end{array}
$$

Pre-CWR hyperthermia

$$
\begin{aligned}
& \begin{array}{lll}
\text { No } & 1 & 1
\end{array} \\
& \begin{array}{lllllll}
\text { Yes } & 1.17 & 0.45-3.02 & .75 & 1.31 & 0.58-2.94 & .51
\end{array}
\end{aligned}
$$

Pre-CWR hormones

$$
\begin{array}{llllllll}
\text { No } & 1 & & \multicolumn{1}{c}{1} \\
\text { Yes } & 0.72 & 0.33-1.60 & .42 & & 0.97 & 0.50-1.88 & .93
\end{array}
$$

\begin{tabular}{|c|c|c|c|c|c|c|}
\hline \multirow[t]{2}{*}{ Factor } & \multicolumn{3}{|c|}{ Overall survival } & \multicolumn{3}{|c|}{ Disease-free survival } \\
\hline & HR & $95 \% \mathrm{CI}$ & $P$ value & HR & $95 \% \mathrm{CI}$ & $P$ value \\
\hline \multicolumn{7}{|c|}{ Resected specimen } \\
\hline $\begin{array}{l}\text { Skin }+ \text { soft } \\
\text { tissue }\end{array}$ & 1 & & & 1 & & \\
\hline $\begin{array}{l}\text { Bone } \\
\qquad(+ \text { other })\end{array}$ & 0.86 & $0.38-1.98$ & .73 & 0.99 & $0.48-2.06$ & .99 \\
\hline \multicolumn{7}{|c|}{ Size resection surface } \\
\hline$<150 \mathrm{~cm}^{2}$ & 1 & & & 1 & & \\
\hline$\geq 150 \mathrm{~cm}^{2}$ & 2.32 & $1.08-4.98$ & .03 & 2.4 & $1.22-4.70$ & .009 \\
\hline \multicolumn{7}{|l|}{ Radicality } \\
\hline No & 1 & & & 1 & & \\
\hline Yes & 1.82 & $0.85-3.89$ & .12 & 0.84 & $0.46-1.53$ & .57 \\
\hline \multicolumn{7}{|l|}{ Bone invasion } \\
\hline No & 1 & & & 1 & & \\
\hline Yes & 1.32 & $0.67-2.59$ & .42 & 1.19 & $0.65-2.20$ & .57 \\
\hline \multicolumn{7}{|l|}{ Ulceration } \\
\hline No & 1 & & & 1 & & \\
\hline Yes & 1.67 & $0.64-4.37$ & .29 & 1.06 & $0.44-2.50$ & .90 \\
\hline \multicolumn{7}{|c|}{ Reconstruction bone } \\
\hline No & 1 & & & 1 & & \\
\hline Yes & 0.99 & $0.46-2.12$ & .97 & 1.1 & $0.57-2.15$ & .77 \\
\hline \multicolumn{7}{|c|}{ Reconstruction skin } \\
\hline No & 1 & & & 1 & & \\
\hline Yes & 1.53 & $0.79-2.98$ & .21 & 1.73 & $0.97-3.10$ & .06 \\
\hline \multicolumn{7}{|c|}{ Adjuvant treatment } \\
\hline No & 1 & & & 1 & & \\
\hline Yes & 0.59 & $0.28-1.22$ & .15 & 0.87 & $0.49-1.56$ & .65 \\
\hline
\end{tabular}

Pre-CWR chemotherapy

$$
\begin{array}{llllllll}
\text { No } & 1 & & & 1 & & \\
\text { Yes } & 2.29 & 0.99-5.34 & \mathbf{. 0 5} & & 2.26 & 0.99-5.13 & \mathbf{. 0 5}
\end{array}
$$

Pre-CWR radiotherapy

\begin{tabular}{lllllll} 
No & 1 & & \multicolumn{1}{c}{1} \\
Yes & 0.68 & $0.30-1.56$ & .36 & 0.99 & $0.50-1.97$ & .99
\end{tabular}

Recurrence rate

$$
\begin{array}{llllllll}
\text { First } & 1 & & \multicolumn{1}{c}{1} & & \\
\begin{array}{c}
\text { Second or } \\
\text { more }
\end{array} & 0.86 & 0.42-1.73 & .66 & & 1.44 & 0.79-2.61 & .23 \\
& & & & & &
\end{array}
$$

TABLE 4 continued

$H R$ hazard ratio, 95\% CI 95\% confidence interval, BCT breast-conserving therapy, $M R M$ modified radical mastectomy, $C W R$ chest wall resection

Bold indicates significant values

\section{DISCUSSION}

Extensive isolated $\mathrm{BC}$ recurrence in the chest wall is difficult to manage. It is a challenge to choose the best local treatment. Evidence-based guidelines for multimodality treatment are not yet available for this heterogeneous group of $\mathrm{BC}$ patients. A few reports focus on radiotherapy for all kinds of LRRs after BC and mainly in patients who underwent some type of surgery before radiotherapy was provided. ${ }^{23}$ In $43 \%$ to $68 \%$ of the patients, radiotherapy can provide local control, with a reported 5- and 10-year OS of $36 \%$ to $61 \%$ and $21 \%$ to $35 \%$, respectively. ${ }^{5,23-25}$ In our opinion, these percentages are relatively high because a large number of patients with a small scar recurrence are included, although prognosis seems to be worse when CWR is performed after the failure of radiotherapy for $\mathrm{BC}$ 
recurrences. ${ }^{26}$ No differences in outcome were found between surgery and radiotherapy for small isolated lesions of local recurrence, but aggressive multimodality treatment was usually advised. ${ }^{9,10}$ According to Dutch evidencebased guidelines, surgery is recommended in combination with hormone treatment for estrogen receptor- or progesterone receptor-positive tumors, but the indication for chemotherapy is still unclear. ${ }^{27,28}$ Several reports showed that CWR is a safe and justifiable procedure with low mortality (0 to $4.5 \%)$ and morbidity. ${ }^{12,29-31}$ Differences in the type of complications recorded, together with the wide range of scoring systems in the literature, make it difficult to compare the $38 \%$ complications found in this studywhich varied from slight wound infection that could be treated by antibiotics, to omental necrosis and pyothorax that required additional surgery-with other studies. Mortality in this study is $<1 \%$ and comparable to data reported in the literature.

The 5-year OS in our study is $25 \%$. Most series reported a 5-year OS of $40 \%$ to $60 \% .^{16,29,32-34}$ The DFS at 5 years is $12 \%$ and only a very few series mention their results, varying from $26 \%$ to $67 \%$ (Table 5). ${ }^{35}$ The reason for this difference remains unclear, but patient selection could be an explanation. Also, our study covers a large time period, during which aspects of $\mathrm{BC}$ treatment changed.

Larger series about CWR for BC make no difference between T4 BC invading the chest wall, local recurrence after mastectomy, axillary lymph node recurrence, internal mammary chain recurrence, or solitary sternal metastasis. ${ }^{5,20,36,37}$ On the other hand, our median survival of 40 months is comparable with other data. Also in this series, neither the $\mathrm{T}$ and $\mathrm{N}$ stage nor type of primary surgery, $\mathrm{BCT}$ or MRM, were statistically significant prognostic factors. In all series, the survival curve is slightly declining after 5 years.
Fifty-one percent of our patients do not develop local recurrence within 5 years; this result has been confirmed in another study $(56 \%) .{ }^{16}$

Few authors studied the influence of prognostic factors. Age of $<35$ years, lymph node-negative status at initial presentation, and an interval between initial treatment and CWR of 2 years or 5 years were described as statistically significantly negative prognostic factors for OS and DFS. ${ }^{9}, 12,16,20,29,30,32,33,35,38,39$ The multivariate analysis in this study confirmed prognostic significance of interval (alone) with the best results after 10 years.

If a radical (R0) resection can be expected, CWR should be considered. In this study, the pathologically confirmed R0 resection rate was $64 \%$, which is comparable with another report. ${ }^{30}$ In the literature, correlations between R1 and R0 resection and DFS or OS never reached significance. ${ }^{25,29}$ This was probably the result of postoperative radiotherapy in patients with a R1 resection. In discussions on the best local treatment, CWR is preferable to radiotherapy as the first choice because unsuccessful radiotherapy proved to be an important predictive factor for complications at the time of CWR. ${ }^{40}$ Also, the effect of radiotherapy is less in extended and multifocal LRR, reflected in decreased survival. ${ }^{41}$

The role of adjuvant systemic therapy after CWR remains unclear, but it may be worth consideration. In 1992, a matched control study on all types of LRR treated with excisional surgery and radiotherapy, whether or not followed by chemotherapy or hormone therapy, showed that OS and DFS were greatly prolonged by adjuvant hormone therapy, but not by chemotherapy. ${ }^{5}$ Because the previously mentioned study was an older study, it can be expected that with the availability of new drugs and more effective chemotherapy schedules, the prognosis of patients with CWR for LRR of BC will improve.
TABLE 5 Literature review of overall survival after curative chest wall resection for locoregional breast cancer recurrence

\footnotetext{
* Months median

${ }^{\text {a }}$ Univariate analysis

b After mastectomy only

${ }^{c}$ Multivariate interval 10 years
}

\begin{tabular}{|c|c|c|c|c|}
\hline Study & $\mathrm{n}$ & $\begin{array}{l}\text { 5-y survival } \\
(\%)\end{array}$ & $\begin{array}{l}\text { Local control } \\
\text { (follow-up) }\end{array}$ & Prognostic factors ${ }^{\mathrm{a}}$ \\
\hline Kluiber ${ }^{42}$ & 12 & 27 m med* & & \\
\hline Soysal $^{14}$ & 10 & 33 & & \\
\hline Faneyte 29 & 30 & 45 & & Age $35 \mathrm{y}$, interval $2 \mathrm{y}$ \\
\hline Toi $^{33}$ & 15 & 47 & & Interval $5 \mathrm{y}^{\mathrm{b}}$ \\
\hline Ohuchi $^{32}$ & 16 & 57 & & Interval $5 \mathrm{y}^{\mathrm{b}}$ \\
\hline Kolodziejski $^{43}$ & 13 & 62 & & \\
\hline Lequaglie $^{19}$ & 18 & 30 & & \\
\hline Miyauchi $^{16}$ & 23 & 48 & $56 \%(5 \mathrm{y})$ & \\
\hline Pfannschmidt ${ }^{31}$ & 33 & $41 \mathrm{~m} \mathrm{med}^{*}$ & $85 \%(3 \mathrm{y})$ & Interval $2 \mathrm{y}$, no adjuvant chemotherapy \\
\hline Downey $^{12}$ & 38 & 18 & & Initial node status \\
\hline Warzelhan $^{34}$ & 22 & 58 & & \\
\hline Pameijer $^{30}$ & 22 & 71 & & \\
\hline Van Geel (this series) & 77 & 25 & $82 \%(5 \mathrm{y})$ & Interval, ${ }^{\mathrm{c}}$ chemotherapy before $\mathrm{CWR}$, size \\
\hline
\end{tabular}


To our knowledge, this is the largest study on prognostic factors in CWR performed with curative intent for recurrent BC. Our results confirm that CWR is a safe surgical procedure. Surgery is indicated in patients who have isolated $\mathrm{BC}$ recurrence, even when surgery means a CWR. The longer the disease-free interval, the better the survival outcome. Adjuvant radiotherapy, and for estrogen receptorpositive tumors adjuvant hormone therapy, is indicated. Neoadjuvant systemic therapy may be taken into consideration on a case-by-case basis. With this regimen, it should be possible to obtain local tumor control in approximately half of the patients and even cure at least $25 \%$ of the patients with an isolated extensive recurrence of $\mathrm{BC}$ in the chest wall.

OPEN ACCESS This article is distributed under the terms of the Creative Commons Attribution Noncommercial License which permits any noncommercial use, distribution, and reproduction in any medium, provided the original author(s) and source are credited.

\section{REFERENCES}

1. Recht A, Silen W, Schnitt SJ, et al. Time-course of local recurrence following conservative surgery and radiotherapy for early stage breast cancer. Int J Radiat Oncol Biol Phys. 1988;15: 255-61.

2. van Tienhoven G, Voogd AC, Peterse JL, et al. Prognosis after treatment for loco-regional recurrence after mastectomy or breast conserving therapy in two randomised trials (EORTC 10801 and DBCG-82TM). EORTC Breast Cancer Cooperative Group and the Danish Breast Cancer Cooperative Group. Eur J Cancer. 1999;35: 32-8.

3. Buchanan CL, Dorn PL, Fey J, et al. Locoregional recurrence after mastectomy: incidence and outcomes. J Am Coll Surg. 2006;203:469-74.

4. Haffty BG, Fischer D, Beinfield M, McKhann C. Prognosis following local recurrence in the conservatively treated breast cancer patient. Int J Radiat Oncol Biol Phys. 1991;21:293-8.

5. Halverson KJ, Perez CA, Kuske RR, et al. Survival following locoregional recurrence of breast cancer: univariate and multivariate analysis. Int J Radiat Oncol Biol Phys. 1992;23:285-91.

6. Kurtz JM, Amalric R, Brandone H, et al. Local recurrence after breast-conserving surgery and radiotherapy. Frequency, time course, and prognosis. Cancer. 1989;63:1912-7.

7. Mendenhall NP, Devine JW, Mendenhall WM, et al. Isolated local-regional recurrence following mastectomy for adenocarcinoma of the breast treated with radiation therapy alone or combined with surgery and/or chemotherapy. Radiother Oncol. 1988;12:177-85.

8. Monyak D LS. Breast: locally advanced (T3 and T4) and recurrent tumors. In: Perez CA, Brady LW, editors. Principles and practice of radiation oncology. Philadelphia: Lippincott; 1992. p. 948-69.

9. Le MG, Arriagada R, Spielmann M, Guinebretiere JM, Rochard F. Prognostic factors for death after an isolated local recurrence in patients with early-stage breast carcinoma. Cancer. 2002;94:2813-20.

10. Nielsen HM, Overgaard M, Grau C, Jensen AR, Overgaard J. Locoregional recurrence after mastectomy in high-risk breast cancerrisk and prognosis. An analysis of patients from the DBCG $82 \mathrm{~b} \& \mathrm{c}$ randomization trials. Radiother Oncol. 2006;79:147-55.

11. Sauerbruch F. Beitrag zur Resektion der Brustwand mit Plastik auf die freigelegte Lunge. Deutsche Ztschr Chir. 1907;96: $275-80$.
12. Downey RJ, Rusch V, Hsu FI, et al. Chest wall resection for locally recurrent breast cancer: is it worthwhile? J Thorac Cardiovasc Surg. 2000;119:420-8.

13. Martini N, Huvos AG, Burt ME, et al. Predictors of survival in malignant tumors of the sternum. J Thorac Cardiovasc Surg. 1996;111:96-105.

14. Soysal O, Walsh GL, Nesbitt JC, et al. Resection of sternal tumors: extent, reconstruction, and survival. Ann Thorac Surg. 1995;60: 1353-8.

15. Weyant MJ, Bains MS, Venkatraman E, et al. Results of chest wall resection and reconstruction with and without rigid prosthesis. Ann Thorac Surg. 2006;81:279-85.

16. Miyauchi K, Koyama H, Noguchi S, et al. Surgical treatment for chest wall recurrence of breast cancer. Eur J Cancer. 1992;28A: 1059-62.

17. Noguchi S, Miyauchi K, Nishizawa Y, et al. Results of surgical treatment for sternal metastasis of breast cancer. Cancer. 1988;62: 1397-401.

18. Incarbone M, Pastorino U. Surgical treatment of chest wall tumors. World J Surg. 2001;25:218-30.

19. Lequaglie C, Massone PB, Giudice G, Conti B. Gold standard for sternectomies and plastic reconstructions after resections for primary or secondary sternal neoplasms. Ann Surg Oncol. 2002;9: 472-9.

20. Muscolino G, Valente M, Lequaglie C, Ravasi G. Correlation between first disease-free interval from mastectomy to second disease-free interval from chest wall resection. Eur J Surg Oncol. 1992;18:49-52.

21. Contant CM, van Geel AN, van der Holt B, Wiggers T. The pedicled omentoplasty and split skin graft (POSSG) for reconstruction of large chest wall defects. A validity study of 34 patients. Eur J Surg Oncol. 1996;22:532-7.

22. van Geel AN, Wouters MW, van der Pol C, Schmitz PI, Lans T. Chest wall resection for internal mammary lymph node metastases of breast cancer. Breast. 2009;18:94-9.

23. Schwaibold F, Fowble BL, Solin LJ, Schultz DJ, Goodman RL. The results of radiation therapy for isolated local regional recurrence after mastectomy. Int J Radiat Oncol Biol Phys. 1991;21:299-310.

24. Ballo MT, Strom EA, Prost H, et al. Local-regional control of recurrent breast carcinoma after mastectomy: does hyperfractionated accelerated radiotherapy improve local control? Int $J$ Radiat Oncol Biol Phys. 1999;44:105-12.

25. Chaudary MA, Tong D, Millis R, et al. Loco-regional recurrence following mastectomy for early breast carcinoma: efficacy of radiotherapy at the time of recurrence. Eur J Surg Oncol. 1997;23: 348-53.

26. Snyder AF, Farrow GM, Masson JK, Payne WS. Chest-wall resection for locally recurrent breast cancer. Arch Surg. 1968;97: 246-53.

27. Borner M, Bacchi M, Goldhirsch A, et al. First isolated locoregional recurrence following mastectomy for breast cancer: results of a phase III multicenter study comparing systemic treatment with observation after excision and radiation. Swiss Group for Clinical Cancer Research. J Clin Oncol. 1994;12:2071-7.

28. Rauschecker H, Clarke M, Gatzemeier W, Recht A. Systemic therapy for treating locoregional recurrence in women with breast cancer. Cochrane Database Syst Rev. 2001(4):CD002195.

29. Faneyte IF, Rutgers EJ, Zoetmulder FA. Chest wall resection in the treatment of locally recurrent breast carcinoma: indications and outcome for 44 patients. Cancer. 1997;80:886-91.

30. Pameijer CR, Smith D, McCahill LE, et al. Full-thickness chest wall resection for recurrent breast carcinoma: an institutional review and meta-analysis. Am Surg. 2005;71:711-5.

31. Pfannschmidt J, Geisbusch P, Muley T, Hoffmann H, Dienemann H. Surgical resection of secondary chest wall tumors. Thorac Cardiovasc Surg. 2005;53:234-9. 
32. Ohuchi N, Hirakawa H, Abe M, et al. [Full thickness chest wall resection for recurrent breast cancer with reference to prognostic factors]. Nippon Geka Gakkai Zasshi. 1993;94:745-50.

33. Toi M, Tanaka S, Bando M, Hayashi K, Tominaga T. Outcome of surgical resection for chest wall recurrence in breast cancer patients. J Surg Oncol. 1997;64:23-6.

34. Warzelhan J, Stoelben E, Imdahl A, Hasse J. Results in surgery for primary and metastatic chest wall tumors. Eur J Cardiothorac Surg. 2001;19:584-8.

35. Chagpar A, Meric-Bernstam F, Hunt KK, et al. Chest wall recurrence after mastectomy does not always portend a dismal outcome. Ann Surg Oncol. 2003;10:628-34.

36. Dahlstrom KK, Andersson AP, Andersen M, Krag C. Wide local excision of recurrent breast cancer in the thoracic wall. Cancer. 1993;72:774-7.

37. Willner J, Kiricuta IC, Kolbl O. Locoregional recurrence of breast cancer following mastectomy: always a fatal event? Results of univariate and multivariate analysis. Int J Radiat Oncol Biol Phys. 1997;37:853-63.

38. Chagpar A, Langstein HN, Kronowitz SJ, et al. Treatment and outcome of patients with chest wall recurrence after mastectomy and breast reconstruction. Am J Surg. 2004;187:164-9.
39. Pfannschmidt J, Geisbusch P, Muley T, Dienemann H, Hoffmann H. Surgical treatment of primary soft tissue sarcomas involving the chest: experiences in 25 patients. Thorac Cardiovasc Surg. 2006;54:182-7.

40. Lans TE, van der Pol CC, Wouters MW, Schmitz PIM, van Geel AN. Complications in wound healing after chest wall resection in cancer patients: a multivariate analysis of 220 patients. $J$ Thorac Oncol. 2009;4:639-43.

41. Marcial VA. The role of radiation therapy in the multidisciplinary management of recurrent and metastatic breast cancer. Cancer. 1994;74:450-2.

42. Kluiber R, Bines S, Bradley C, Faber LP, Witt TR. Major chest wall resection for recurrent breast carcinoma. Am Surg. 1991;57:523-9.

43. Kolodziejski LS, Wysocki WM, Komorowski AL. Full-thickness chest wall resection for recurrence of breast malignancy. Breast J. 2005;11:273-7. 